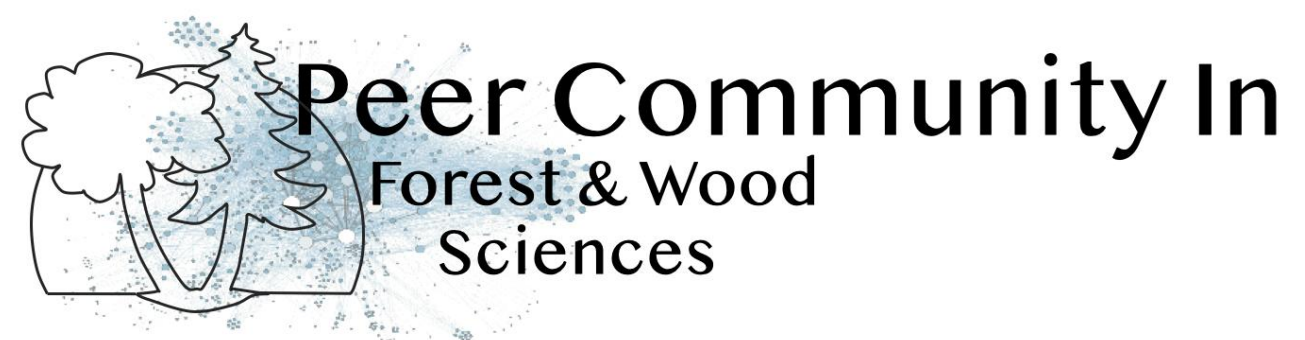

\title{
Into the wood: the biomechanical history of trees revealed by their inner structure
}

Hervé Cochard based on reviews by Barry Gardiner and 1 anonymous reviewer

\section{A recommendation of:}

Tree growth forces and wood properties

Bernard Thibaut, Joseph Gril (2021), HAL, hal-02984734v4, ver. 4 peer-reviewed and recommended by Peer community in Forest and Wood Sciences. https://hal.archives-ouvertes.fr/hal-02984734

\section{Open Access}

Submitted: 06 November 2020, Recommended: 06 July 2021

Published: 12 July 2021

Copyright: This work is licensed under the Creative Commons Attribution-NoDerivatives 4.0 International License. To view a copy of this license, visit http://creativecommons.org/licen ses/by-nd/4.0/

\section{Cite this recommendation as:}

Hervé Cochard (2021) Into the wood: the biomechanical history of trees revealed by their inner structure. Peer Community in Forest and Wood Sciences, 100006. 10.24072/pci.forestwoodsci.100006

\section{Recommendation}

Trees are constantly subjected to mechanical stresses (gravity, wind, storms) but they have a remarkable ability to remain upright despite their great size. Straightness is also major characteristic that greatly determines the quality and market value of a log. For some species, maritime pine in particular, this is even a default that geneticists are trying to correct through dedicated breeding programs (Bartholomé et al. 2016). If trees are able to maintain a straight trunk, or to return to straightness after a growth accident, for example, it is thanks to an "engine" whose mechanisms are now better known (Moulia et al. 2021). This mechanism lies in the structure of the trunk itself and the ability of trees to produce cells and tissues that display different mechanical properties during their maturation. Some fibers will "pull" the trunk in one direction, known as tension wood, while others will « push » it in the opposite direction (compression wood). The posture control of a tree is therefore directly related to the growth process of the trees and the placement of this reaction wood at specific points in the trunk. The internal structure of the trunk will therefore retain the memory of these growth constraints throughout its life and, if we are able to read it, we can envisage reconstructing its history over the years. This source of information contained in tree rings is still largely unexplored. However, it can reveal insights into the evolution of the climate, or help foresters to select the most valuable trees. Sophisticated approaches exist to measure these growth forces in wood, but the major difficulty remains our ability to read the mechanical properties with simpler, more widely used methods. The article by Thibaut and Gril (2021) proposes such a methodology.

The approach used here is similar to the one used for other wood functions, such as sap transport: linking the mechanical function of wood to its structural properties. The transport capacity of wood is for example well explained by the 
distribution of vessel sizes. However, other interesting properties, such as resistance to cavitation, are only very weakly explained by the same anatomical characteristics. The authors, after analyzing the wood properties of many species, both tropical and temperate, conclude that growth forces can be deduced from variables that are relatively simple to measure, such as wood density or moduli of elasticity. The article provides a series of generic and more specific equations and relationships that allow these growth forces to be estimated.

I recommend this article to people who want to learn about the principles and concepts of tree biomechanics. I also recommend it to people who want to further explore the mechanical properties of trees and who will be able to characterize them thanks to the method proposed here by the authors.

\section{References}

Bartholomé J, Bink MC, Heerwaarden J van, Chancerel E, Boury C, Lesur I, Isik F, Bouffier L, Plomion C (2016) Linkage and Association Mapping for Two Major Traits Used in the Maritime Pine Breeding Program: Height Growth and Stem Straightness. PLOS ONE, 11, e0165323. https://doi.org/10.1371/journal.pone.0165323

Thibaut B, Gril J (2021) Tree growth forces and wood properties. HAL, hal-02984734, ver. 4 peerreviewed and recommended by Peer community in Forest and Wood Sciences. https://hal.archivesouvertes.fr/hal-02984734

Moulia B, Douady S, Hamant O (2021) Fluctuations shape plants through proprioception. Science, 372. https://doi.org/10.1126/science.abc6868

\section{Reviews}

Toggle reviews

\section{Revision round \#2}

2021-06-09

\section{Author's Reply}

Download author's reply (PDF file)

\section{Decision round \#2}

Dear authors, dear colleagues,

Your manuscript has been reviewed by a referee who has already evaluated your paper.

Unfortunately, we were unable to obtain an evaluation from the second referee.

The referee has made a number of relatively minor comments and requests (see pdf) that you can easily address I think during your final revision. I agree with him that the objectives of your paper are now better formulated and I believe this will greatly improve its readability.

Thank you for considering the PCI Forest \& Wood Sci and I look forward to receiving your revision soon.

Yours sincerely, 


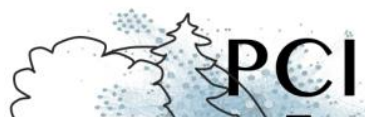 Wood Sci}

\section{Reviewed by Barry Gardiner, 2021-06-01 07:39}

The paper is much better now and there is a clear idea and purpose. I would have liked to see some estimation of uncertainty in the "model" equations provided but this would mean a much more "modelling" approach and I think the work presented is too valuable to not publish now. Maybe the authors can consider in the future are more thorough approach using linear mixed models and looking for the best models to describe each parameter of interest.

\section{Revision round \#1}

2021-01-13

\section{Author's Reply}

Download author's reply (PDF file)

\section{Decision round \#1}

Dear authors, Thank you for submitting your preprint to PCI and I apologize for the somewhat long delay in returning my decision. Your preprint has now been reviewed by 2 external referees and myself. The referees both found your dataset very valuable and important. The subject of this paper is also very relevant to our community and represents an important contribution in this area.

Referees also noted problems, especially with its form, which make it difficult to understand and read your work. My reading, less expert than theirs, also confirms this impression. The referees have made many suggestions that I think will improve the attractiveness of your preprint. I would like to draw your attention to the quality of the figures which can indeed be improved quite easily. I also invite you to restructure some paragraphs (well dissociate what is part of the M\&M and Results sections) and, as one of the readers points out, to better tell a "story". I realize that these changes require some formatting and writing work but I think they will contribute greatly to the quality of your pre-print. In addition, the referees have made a number of comments that I also invite you to take into account in your review. Thank you again for considering PCI Forest \& Wood Sciences for your submission. Hervé Cochard

Preprint DOI: https://hal.archives-ouvertes.fr/hal-02984734

Reviewed by Barry Gardiner, 2021-01-08 08:31

Download the review (PDF file)

Reviewed by anonymous reviewer, 2021-01-08 07:14

Download the review (PDF file) 